\title{
Investigating the Relationship of Working Memory and Inhibitory Control: Bilingual Education and Pedagogical Implications in Elementary School
}

\author{
Maria Sofologi \\ School of Education Sciences, University of Ioannina, Greece \\ https:// orcid.org/0000-0003-0380-2220 \\ Makrina Zafiri \\ Aristotle University of Thessaloniki, Thessaloniki, Greece \\ https://orcid.org/0000-0002-0685-3181
}

Vassiliki Pliogou

School of Humanities and Social Sciences, University of Western Macedonia, Greece https:/ / orcid.org/0000-0002-1009-0287

\begin{abstract}
Present study aims to shed light on the relationship of working memory and executive functioning in bilingual elementary school children when compared with monolingual population of the same age. The investigation of the relationship between working memory and language learning abilities of children, who are bilingual, is particularly important as it plays a key role in understanding the literacy and language competence of bilingual populations. The purpose of this study was to examine Verbal Working Memory and Executive Functions in 20 bilingual elementary school students who were compared to 20 monolingual school-age students in different cognitive tasks. The research results showed that bilingual students did not appear to perform better in Working Memory compared to the performance of monolingual students of the same age. Correspondingly, bilingual students performed better in the task of inhibitory control and cognitive change. The findings of the present study reinforce the hypothesis that when learning a language, be it the mother tongue or the foreign / second language, the working memory does not correlate to all executive functions but forms a separate cognitive function. The implications of bilingual learning strategies in multicultural class settings are discussed as a pedagogical memory frame that can empower academic achievement while acknowledging the importance of acquiring standardized language skills by promoting a variety of memory strategies.
\end{abstract}

Keywords: Bilingual Education; Mother Tongue; Foreign /Second Language; Working Memory; Executive Functions; Elementary School 


\section{Introduction}

In modern societies, many countries and states are called upon to deal with bilingualism or multilingualism and, at the same time, many are experiencing problems concerning this phenomenon on a daily basis. Bilingualism is that part of linguistics which deals with language learning and teaching as well as with education, in its wider sense; it also deals with the socio-political factors which influence bilingualism. The phenomenon of dual language proficiency is generally used for whole societies, communities, or individuals. Language diversity is closely related to the alternative use of two or more languages by the same person and occurs when two or more people, who speak a different language, are forced to communicate using a common - verbal - code of communication. A bilingual person is able to use two language codes of communication, very comfortably, to meet their daily communicative needs (Gollan \& Ferreira, 2009; Golberg, Paradis \& Crago, 2008). It should be noted, however, that the language proficiency shown by a bilingual speaker who uses the two languages interchangeably to communicate, is found to depend on both the duration and the manner in which the second or foreign language was acquired and, on the other hand, the involvement of the speaker himself or herself (Namazi \& Thordardottir, 2010; Pineda, 2010).

In an attempt to illustrate the complexity of this multi-dimensional phenomenon and its impact on school performance, the research community has attempted to investigate the relationship of bilingualism with working memory and executive functions. Research has focused on the investigation of this relationship in order to create a prognostic indicator which will deal with the academic achievement of bilingual students (de Abreu, Cruz-Santos, Tourinho, Martin \& Bialystok, 2012). This research attempts to shed light on the challenges teachers face in their class when asked to deal with students who are linguistically diverse. More specifically, this research proposes a series of examples of practice, or memory strategies, to embrace bilingual students. Furthermore, language teaching indicates that students' language-minoritized is expected to replace their home language varieties with the standardized national language. For this reason, the importance of developing innovative teaching practices is essential in order to minimize the gap which exists in language diversity. In this research, we seek to highlight a number of strategies that could be used in order to avoid reproducing a form of 'stigmatization' of the language used by minority students. As a result of language diversity, the ideology of language inequality can be resolved with appropriate memory strategies, which could be applied when learning a language within a school setting.

\section{What is Bilingualism?}

Speakers of languages live in language communities; some of these communities may use two or more languages as formal communication codes. Many people who live in these communities may be competent and may also have a sound command of two languages; this is called bilingualism. Bilingualism is part of a wider social and political movement what Wei $(2005$, p. 10) calls "[...] a sociopolitical issue [...]". It is important to note that there are two types of bilingualism, namely, bilingualism as an individual phenomenon and 
bilingualism as a societal phenomenon (Hoffman, 2014). When we say that someone is bilingual, we mean that he or she is competent in two languages. The question that arises here is whether the bilingual person is competent in all four of his or her skills, namely listening, speaking, reading and writing. There is no rigid or set answer to this question in the sense that a person may speak two languages but may use one language to communicate verbally and the other to write or to read. Or, they may understand the language when they hear the language spoken or when they read a text written in the aforementioned language, but the same person may not speak or write the language; this is called passive bilingualism (Slavkov, 2014). Still others understand a spoken language without speaking it themselves (Bligh \& Drury, 2015). This is why proficiency and use of language, especially amongst bilinguals, do not always correlate. Another factor that should be considered is that the four basic language skills mentioned above are not the only ones that exist today. According to Skutnabb-Kangas (1981), a language which we have and use in our mind may be the fifth level of language proficiency or skill. In this case, a person may not speak, hear, read, or write a language, but he or she may still use it as a kind of internal speech or as a kind of tool of thought. Cummins (1984) called a person's cognitive ability in a language, the ability to use one or both languages for thought and reflection.

\section{Bilingual Education}

According to Baker (1993), bilingual education may sometimes refer to native speakers of two languages, but it may also refer to students who are in the process of studying a foreign or second language. We should also not confuse foreign or second language teaching with bilingual education because teaching a foreign language is teaching the language as a subject, whereas, in bilingual education the language becomes the medium of instruction (Bacha, 2019). Bilingual education should also not to be confused with bilingual child-raising (McCarty, 2010), which is basically the speaking of two languages to an infant systematically at home. Bilingual education should involve teaching school subjects in two or more languages at school. Bilingual education should be meaningful education, on the one hand, and on the other hand it should show an understanding towards other languages and cultures (Ozfidan \& Toprak, 2019), thus reinforcing the respect of diversity and social coexistence in a multicultural environment from the perspective of Intercultural Education (Palaiologou \& Dietz, 2012 ; Pliogou \& Karakatsani, 2020).

\section{Pedagogical implications of Bilingualism and Bilingual Education}

Bilingual Education according to Hurajova, (2015, p.4), consists of "[...] two languages that are used as media of instruction in educational contexts [...], in other words, two or more languages are used as media of education, and there is an integration of topic and language (in this case it may be the integration of more than two languages compared to foreign language teaching). When educating a bilingual learner, we, as teachers, expect that he or she will be able to function globally across cultures (Bacha, 2019). Mehisto $(2012$, p. 8) suggests that there are potential benefits to individuals, schools and societies in being or becoming bilingual, for example, there is an "increased mental flexibility", there 
are "improved inter-cultural skills" and, last but not least, there are "increased opportunities for global exchange and trade". We thus see the important role played by the appropriate choice and application of the method of teaching, the teaching approach, and the technique which should be applied to bilingual students. For bilingual students, the appropriate method, approach, and technique or a combination of methods, approaches, and techniques may lead to successful learning of both languages by the student. More particularly, Experiential Learning, Project Work, Exploratory Teaching, Content and Language Integrated Learning (CLIL), and an Eclectic Approach to teaching bilingual students could be applied to facilitate their leaning. What follows is a short presentation of the aforementioned methods and approaches.

Experiential teaching (and learning) is a life experience, it is a kind of "learning in which the learner is directly in touch with the realities being studied. It is contrasted with the learner who only reads about, hears about, talks about or writes about these realities but never comes into contact with them as part of the learning process", as Keeton and Tate $(1978$, p.9) put it. In a sense, experiential teaching (and learning) is the direct connection of a student's experience with the context of what he or she is taught. It is what Kolb (1984) calls the process whereby knowledge is created through the transformation of experience. Kolb's (1984) model presents a four-step procedure, namely that students have their own concrete experiences upon which they reflect from a variety of perspectives. These reflective observations allow students to go through a process of abstract conceptualization, creating generalizations which then help them to integrate what they observe into theories, which in turn help them to engage in experimentation through which they test what they have just learnt in other more novel - cases. Experiential teaching (and learning) is one of the best methods of teaching bilingual students as it allows them to transfer the knowledge they have of the one language, to the other language, thus engaging in a new set of experiences, and thus progressing to a more advanced level of learning (Kolb, 1984). Studies have shown that students' believe that when teachers move away from traditional teaching models in bilingual education and towards a more experiential model of learning, this then boosts their second language acquisition while at the same time it triggers their curiosity about the cultural similarities and differences of the two languages (Moreno-López, Ramos-Selman, Miranda- Aldaco \& Gumis-Quinto, 2017).

Project work or the project method of teaching is a student-centered and teacherfacilitated method of teaching which helps students to acquire and apply their knowledge and skills to solve a problem (Duke 2016). The project method was first introduced by Kilpatrick (1925) at the beginning of the twentieth century and since then it has come a long way and is diligently applied at a global scale. It is a method of teaching and learning through acting and experiencing, as well as problem-solving (Gutek, 2003). The project method is also applied in teaching the second or foreign language to bilingual or non-bilingual students. Kolber (2017) emphasizes upon the advantages of the project method in second or foreign languages teaching, especially when the project meets the student's needs and expectations. Project work is applicable in bilingual education, especially since we want to help students develop their independence and confidence in both languages (Fried-Booth, 2002), students' autonomy is also 
enhanced in project planning (Skehan, 1998), and so is "their self-esteem, and positive attitudes toward learning" (Stoller, 2006, p.27). Social cooperation and group cohesion are enhanced in bilingual education and project work, and so are improved language skills (Levine, 2004), since in project work there is a "natural integration of language skills" (Stoller, 2006, p.33), and students participate in verbal communication so as to complete authentic activities (designed to develop students' thinking and problem solving skills) in an almost natural context (Haines, 1989), using authentic language. We thus see that the pedagogical benefits of project based teaching and learning are twofold in the sense that bilingual students don't only develop their language learning skills and show an increased interest and motivation to participate and to promote their learning (Brophy, 2004), and also to cultivate their higher order critical thinking skills (Allen, 2004), but they also develop a sense of cooperation and group cohesion which are important in project based teaching and learning.

Exploratory instruction, as the name suggests, offers students the opportunity to search for their own ways to learn the new material which they have been presented with. More specifically, (see Education Service Center Region XIII, 2009), the student:

-Thinks creatively within the limits of the activity.

-Tries alternatives to solve a problem and discusses them with others.

- Conducts activities, predicts, and forms hypotheses or makes generalizations.

-Becomes a good listener.

-Shares ideas and suspends judgment.

- Records observations and/or generalizations.

-Discusses tentative alternatives.

The teacher on the other hand:

- Elicits responses that uncover students' current knowledge about the concept/topic.

- Raises questions and problems.

- Acts as a facilitator.

- Observes and listens to students as they interact.

- Asks good inquiry-oriented questions.

- Generates interest.

- Generates curiosity.

Exploratory instruction is, as we can see, a student-centered pedagogy and teacher-facilitated method of teaching. It is a teaching method which encourages students to explore new concepts, knowledge and material, especially through the use of multimodal texts, and to compare this new knowledge to already existing or 'old' knowledge, thus making inferences. This is the reason why it is considered one of the best teaching methods in bilingual education as it allows the student to compare already existing knowledge, in the one language, to the newly acquired knowledge of the second language (Kolb, 1984). 
Content and Language Integrated Learning (CLIL) is a fairly recent approach to second and foreign language teaching. More particularly, in CLIL, content from subjects across the curriculum is taught, wholly or partly, through the medium of another language, English, for example. CLIL focuses on teaching both the subject and the language together in this way students learn to communicate both verbally (Delliou \& Zafiri, 2016), and in writing (Olson 2015), about the subject they are learning, for example Geography (Korosidou \& Griva 2013), using the language which they are learning. Emphasis is given to vocabulary learning as CLIL adopts a lexical approach to language teaching and learning (Mehisto, Marsh \& Frigols, 2008), while emphasis is given to the cultivation of all four skills by students. CLIL thus acquires a pivotal place in pedagogics and in language teaching and learning, as it promotes self-efficacy in students and a deeper understanding and learning of the target language thus "moving pedagogic thinking forward-beyond the bilingual classroom", as Coyle (2018, p. 166) puts it.

The eclectic approach to language teaching combines various approaches and teaching methods to teach a language depending on the aims of the lesson, the language level of the students, and their abilities. Larsen-Freeman (2011) and Mellow (2002) used the term 'an eclectic approach' to language teaching meaning that different teaching methods are borrowed and adapted to suit the demands or needs of the students. Wali (2009) describes the eclectic approach as follows "[...] one of the premises of eclecticism is that teaching should serve students not methods [...] (see Wali, Sproat, Padakannaya \& Bhuvaneshwari, 2009). This is the reason why teachers should be able to choose the methods, approaches and techniques which they wish to apply in their class. According to the tenets of the eclectic approach there is no ideal method, approach or technique in language teaching and learning, it all depends on the students' needs, language level, and abilities. Teachers are free to apply any method, approach and technique to serve the needs of their students; this is the reason why it is an approach which is highly valued in bilingual teaching.

\section{Working Memory and Bilingual Students}

There is a growing body of literature which illustrates contradictory findings, to date, generating two very distinct research approaches. More particularly, according to the first framework, a number of contemporary relational studies have argued that the types of different cognitive tools, which are used to assess working memory, affect the performance of bilingual students compared to monolingual students (St Clair-Thompson \& Gathercole, 2006; St Clair Thompson, Hunt \& Bolder, 2010). As concerning the relationship between working memory and bilingualism, Bialystok (2011) argues that the ability which bilinguals have to inhibit one language while using the other increases their working memory capacity as working memory appears to be controlled through the aforementioned mechanism. Over time, research data reveals that in cognitive assessments which require strong attention spans, bilinguals exhibit greater working memory capacity than monolinguals (Kane \& Engle, 2002; Robbins \& Arnsten, 2009; Schneider, Kron-Sperk, Hünner \& 2009).

Documentation of the above research finding is confirmed by a number of studies suggesting that bilingual students exhibit better performance on 
executive control assessment tools requiring selective attention and inhibition when compared with the performance of monolingual students (Blom et al., 2014; Morales, Calvo \& Bialystok, 2013). The research community argues that bilingual, very young, students can steadily and systematically activate executive functions and, in particular, cognitive flexibility because of their ability to use both languages simultaneous or to use one of the two languages when this is deemed necessary (Abutalebi, Della Rosa, Green, Hernandez, Scifo, Keim \& Costa, 2011). Cognitive flexibility (cognitive switching) refers to the ability a person or a learner has to switch between different tasks without causing a problem in performance in any of the tasks and in any of the languages when the person or the learner is bilingual. The aforementioned is an important component of executive control (Dana-Gordon, Mazaux \& Kaoua, 2014; Greene, Braet, Johnson \& Bellgrove, 2007).

\section{Executive Functions and Bilingual Students}

The advantage of cognitive flexibility is often endorsed by the research community as the view that "improved" executive functions appear to empower bilingual populations. Furthermore, "improved" executive functions seem to enhance bilingual children to focus their attention, a lot better, while engaging in a cognitive task, while at the same time they seem to improve their problemsolving skills immensely from early childhood to adulthood (Abutalebi et al., 2011). Nevertheless, in the course of time, according to Bialystok (2011), when the two languages which are spoken by the bilingual become active, then a problem of attention arises which does not seem to exist in monolinguals. Bilinguals, more frequently, use inhibition control to resolve this problem of attention and thus achieve better performance in inhibitory tasks throughout their lives when compared with monolingual populations.

The aforementioned stance is supported by a number of studies in which bilingual students appear to perform better in executive tasks compared to monolingual students (Hernandez, 2009), especially in processing speed evaluation tasks (Bialystok, 2011), in using symbols, in understanding the inverse use of numbers, in the comprehension of object stability (Adesope, Lavin, Thompson \& Ungeleider, 2010) and finally in non-verbal creativity tests (Carlson \& Meltzhof, 2008). Consequently, bilinguals are found to be more active in executive functions through the continuous management of rotation skills that require flexibility and inhibition (Hernandez, 2009; Luk \& Bialystok, 2013).

Additionally, it is argued that both early and delayed acquisition of two or more languages is associated with the ability to exercise cognitive flexibility when executing multiple tasks. And that the simultaneous learning of two language systems provides essential key elements which are necessary for a learner's cognitive background as it also increases their executive effectiveness. It is believed that bilingualism can reduce any interference from irrelevant environmental irritants. Therefore, in this way, a bilingual person can work more effectively in everyday situations where a variety of stimuli occur while at the same time, they can ignore the irrelevant information in the work which is being processed (Alvarez, Emory \& Julie, 2006; Berroir, Ghazi-Saidi, Dash, Adrover-Roig, Benali \& Ansaldo, 2017). 
In contrast to the above research perspective there are a number of crosssectional studies the findings of which support the theoretical view that bilingual students, of elementary school age, do not appear to be advantageous in their performance compared to monolingual students in their executive functions and in their working memory (Namazi et al., 2010). More specifically, according to this research concept, the working memory of bilinguals is considered to be affected in some cases by the use and practice of the two languages, thereby increasing the cognitive load and weakening the ability of the inhibitory control (Lehtonen, Soveri, Lane, Järvenpää, de Bruin \& Antfolk, 2018; Yang, 2017).

\section{Relationship between working memory and executive functions on the performance of bilingual students}

Building upon this theory and research the present research study attempts to investigate the significant relationship between working memory and executive functions as well as their combined impact on the performance of bilingual elementary school students. According to the first research hypothesis, bilingual students are expected to achieve a better performance on working memory tasks when compared to monolingual students of the same age (Bloom et al., 2014) (Hypothesis, 1).

The relationship between the phonological working memory and the second or foreign language is confirmed and supported by a number of research studies (Gathercole, Briscoe, Thorn \& Tiffany, 2008). Researchers emphasize on the fact that verbal working memory capacity is related to competence when acquiring a foreign language. Over time, working memory has been found to affect the extent to which stable phonological representations are created in long-term memory (Gathercole \& Baddeley, 1990). As for the second research hypothesis, we assume that bilingual students can perform better in visual and spatial retention tasks (Hypothesis, 2). More particularly, we hypothesize that the working memory of bilingual students in cognitive fields of management, in immediate retention and storage of visual and spatial information differs from that of monolingual students. Research has revealed that visual-spatial working memory is involved directly in learning a language and more particularly during the reading process. Alongside the phonological function, the processing of a foreign language obviously requires a visualization strategy which is related to the requirements of the visual-spatial working memory (Kim, Relkin, Lee \& Hirsch, 1997). In elementary school students the function of visualization, for which the visual-spatial notebook is responsible, is just as prominent as the phonological function for which the phonological circuit is accountable. The function of visualization is essential for the learning of the mother tongue as well as the learning of a foreign language, as it is involved in reading and learning vocabulary terms. Finally, according to the third hypothesis, it is expected that bilingual students will perform better on inhibition tasks than monolingual students of the same age (Hypothesis, 3). Michael and Gollan (2005) suggested that inhibition may be what links working memory and language learning. This means that bilingual students can acquire better working memory skills than monolingual students because using two or more languages requires a specific 
metacognitive skill, namely that, when using the one language then the other language should not interfere (Morales et al., 2013).

\section{Methodology}

Participants and settings

For the purposes of the present research study, 40 elementary school students of the fifth grade aged 11 years were evaluated. More specifically, two groups were created, the experimental group, which consisted of 20 Greek bilingual elementary school students of the fifth grade aged 11 years (10 boys and 10 girls) who spoke French and Greek. The bilingual students were studying in a Greek school in the city of Paris. The control group consisted of 20 monolingual pupils who were 11 years old and studied in the fifth grade at different state schools (10 boys and 10 girls). The Greek-speaking monolingual students came from Thessaloniki which is the second-largest city in Greece. The participants of both groups came from different socioeconomic strata based on their parents' educational level and profession.

\section{Procedure}

The examination of all bilingual participants was individual and took place in a quiet school-room. The evaluation of monolingual students was administered in a private room after the researchers' consultation with the parents of the participants. Students who participated in the present study had no official diagnosis of special learning difficulties, mental disabilities (based on their teachers and their parents), or sensory impairments. Prior to the study and in collaboration with the school committees and the principal from every school, parents gave their written consent statement for the participation of their children in this study. Furthermore, for all the principals and the parents of the children an informed letter was obtained in order to clarify the objectives of the study and the anonymity of the participants as well. Additionally, the participants were informed that they were free to withdraw from testing at any time. Parents whose children met the inclusion criteria received a package containing an informative letter about the study and its purpose and a consent form. The data collection was carried out from January 2020 to April of the same year.

\section{Instruments}

The evaluation of Verbal Working Memory was conducted with the implementation of the Forward Digit Recall and Backward Digit Recall (Georgas, Paraskevopoulos, Bezeveggis \& Giannitsis, 1997) whereas Visual Working Memory was assessed with the assessment instrument of Visual Pattern Recall (VPT) (Della Sala, Gray, Baddeley, Allamano \& Wilson, 1999) and Block Backward Test (Farrell Pagulayan, Busch, Medina, Bartok \& Krikorian, 2006). Both sub-scales are culturally neutral, and they also include general shapes, with no verbal fragments. The following projects were used to evaluate and measure the immediate visual retention of stimuli to investigate the direct involvement of the visual sketchpad: Visual Pattern Test (VPT) and Corsi Block Backward Test (Corsi Bw). 


\subsection{Working Memory Measurements}

Forward Digit Recall The verbal subtest of Digit Recall test (forward and backward recall) is part of the WISC-III standardized Greek version assessment tool (Georgas et al., 1997). The task of digit recall consists of 15 complex gradient arithmetic sequences. In this project, the researchers reads a list of digits or a series of digits at a rate of one digit per second each time, and the participant is asked to recall it in the same order. The use of the Digit Recall Scale aims at evaluating participants' working memory. The task of the individual is to repeat each sequence either from the beginning to the end (straight repeat) or from the end to the beginning (reverse repeat). Each question contains two rows, each with the same number of digits. The first row in the pair is Attempt 1, and the second row is Attempt 2. In the process of direct repetition, the individual is asked to recall a total of eight pairs of rows correctly. Correspondingly for the reverse iteration, it must retract a total of seven pairs of rows. The evaluation process in the straight repetition starts with Question 1, which is given to all participants. The evaluator evaluates both attempts to each question, even if the participant has succeeded in Attempt 1 . The main process is interrupted after a failed retry in both attempts. This cut-off criterion applies to both straight-repeat and reverse-repeat questions. The evaluator is required to provide the reverse repetition questions, even if the participant has scored zero points in the direct repetition process.

\section{Backward Digit Recall}

Backward digit recall is preceded by a familiarization process, where the evaluator provides an example of a sequence of digits and the participant is asked to recall it in the reverse order. If the participant answers correctly, the familiarization process is completed and the evaluator answers Question 1. If a wrong answer is given, a second example of familiarization is given. Upon completion of the second example, the evaluator provides Question 1 regardless of whether the participant answered correctly or incorrectly. Each question is scored with 2 points if the participant succeeds in both attempts of the question, with 1 point if he successfully revokes only one of the two attempts of the question, and with zero points if he fails to recall the sequence of digits in both attempts at the question. The total sum of the straight digits recall comes from all the successfully replicated answers. Accordingly, the sum of the correct answers for the backward digit recall is the sum of the correct answers. The degree of the scale is the sum of the units in the two parts of the scale, that is, the total sum of the straight repeat is added to the total of the reverse repeat. The maximum number of points in a forward repeat is 16, while in the backward digit recall, it is 14 . The upper point of the scale is 30 .

\subsection{Visual Working memory (working memory visual sketchpad)}

Visual Pattern Recall (Della Sala et al., 1999)

This cognitive assessment tool is used to measure visual short-term memory. The assessment consists of visual shapes (42 in total), which the participant is asked to reproduce immediately after the presentation. More specifically, the examiner presents a series of tabs in which there are combinations of squares, some of which are black and white. The participant is called upon to reproduce the previously presented image by tinting in the corresponding squares' 
response protocol with those originally seen on each tab under consideration. The complexity of the test varies as it proceeds. The visual shapes vary in size from the smallest $(2 \times 2$, i.e. two designed squares) to the largest shape $(5 \times 6$ squares, that is, 15 designed squares). Each card is presented to the participant for three seconds and then removed from his or her field of view and then he or she is asked to reproduce in pencil and paper the shape which he or she has just seen. The answer booklet is placed in front of each participant, with the corresponding blank shapes, which are exactly the same dimensions as the original visual shapes. The criterion for the process interrupting is the unsuccessful reproduction of two visual shapes in each field, regardless of the complexity of the design. Participants are graded in two ways: a) according to the total number of shapes successfully reproduced (Maximum Score $=24$, Minimum Score $=0$ ) and $b$ ) a field is defined as the sum of the squares of the last field which was correctly recalled (Maximum Score $=8$, Minimum Score $=0$ ).

\section{Block Backward Test (Corsi Bw)}

The Corsi Block Test consists of nine cubes perched on a rectangular wooden surface. Each cube is numbered from 1 to 10 (the numbers are visible only to the researcher). The researcher touches two or three, consecutive cubes at a time and the participant is asked to reproduce the sequence he or she has just seen. Touching each cube takes one second. The difficulty level fluctuates between fields, starting with one cube in the first field and reaching nine in the last one. People with left temporal lobe deficit perform poorly while education and age are factors that influence performance. Each field comprises a total of six attempts. Responses are scored 1 if they are correct and 0 if they are unsuccessful. This score gives the total number of correct answers. The final score corresponds to the sum of the correct answers (Maximum Score $=54$, Minimum Score $=0$ ). The mnemonic field score corresponds to the maximum number of cubes contained in the order of the last field which was correctly recalled (Maximum score $=9$, Minimum score $=0$ ).

\subsection{Measuring Executive Functions}

The Stroop Test was used to measure and evaluate students' inhibitory control. The purpose of the Stroop test is to measure the ability the participant has to inhibit and switch a response. The format we used includes a series of repetitive words which are 'red', 'blue', 'green', each of which is printed randomly in red, blue, or green ink. The word may not be written in the respective color of the ink, in other words the word blue may not be written in blue ink but in red ink. This tool consists of three parts. The first part of this tool has three names of colors which are printed in ink (blue, red, green), and the participant is asked to voice the color he or she sees, out aloud. The second part has the XXX symbols printed in color and the job of the participant is to call out the color of the ink which is printed each time. Finally, the third part of the evaluation has color names which are printed in ink but the color of the ink and the word do not correspond, for example, the word red is printed in green. The participant is asked to name the color of the ink, not the printed word. The main purpose here is to encourage the participant to name the color but not to read the word which is presented each time. The total result is derived from the total number of items that the participant will read within 45 seconds. The rating is based on the 
number of errors that the examiner made and did not correct and the time it took to complete the test in seconds.

\subsection{Data Analysis}

The data were analyzed using the SPSS 23. Initially, in an attempt to evaluate the data of the current study we evaluate mean differences of the participants from both groups in order to evaluate their cognitive performances in different cognitive tasks. In the next step of the statistical analysis different repeated measures ANOVA (also referred as a within-subjects ANOVA)were applied in order to test and detect any overall differences in performances between related means between the bilingual children and monolingual elementary school children in cognitive measures.

\section{Results}

Table 1 presents the average and standard deviations of the participants of the two groups' regarding their performance in Working Memory and Executive Control tests.

Table 1. Averages and Standard Deviations for both groups

\begin{tabular}{|l|c|c|c|c|}
\hline & \multicolumn{2}{|c|}{ Bilingual Students } & \multicolumn{2}{c|}{ Monolingual Students } \\
\hline & M.O & T.A & M.O. & T.A. \\
\hline Forward Digit Recall & 20.18 & 7.14 & 21.20 & 2.33 \\
\hline $\begin{array}{l}\text { Backward Digit } \\
\text { Recall }\end{array}$ & 14.74 & 4.02 & 15.01 & 3.36 \\
\hline Word Recall & 22.40 & 2.83 & 21.20 & 2.33 \\
\hline $\begin{array}{l}\text { Visual Patterns } \\
\text { Recall }\end{array}$ & 18.23 & 4.03 & 14.57 & 4.45 \\
\hline Stroop Part A & 43.08 & 7.61 & 37.56 & 10.02 \\
\hline Stroop Part B & 38.07 & 7.91 & 32.76 & 10.28 \\
\hline Stroop Part C & 28.3 & 7.45 & 23.4 & 8.61 \\
\hline
\end{tabular}

In order to evaluate the first hypothesis concerning the possible difference in the performance of both groups (bilingual and monolingual students) in the verbal working memory tasks a variance analysis was conducted with independent variables to the participants of both groups and the same goes for the dependent variables of their performance in all working memory verbal tasks. More specifically, the analysis of variance for the Forward Digit Recall test did not show a statistically significant difference in the performance between the two groups $F(2.38)=4.19, p>.05$, whereas a non-statistically significant difference in performance was found between the two groups for the Backward Digit Recall Task $F(2,38)=2.68, p>.05$. Concerning the Word Recall test, the analysis of variance did not reveal any statistically significant difference in the performance of the two groups $F(2,38)=1.69, p>.05$. The findings do not confirm the first research hypothesis. It was expected that bilingual elementary school students 
will perform better in the Verbal Working Memory tasks compared with monolingual students.

In the next part of the analysis, and in order to evaluate the hypothesis that the performance of the two groups will differ in the Visual Pattern task, an analysis of variance was performed. The analysis of variance showed a statistically significant difference $F(2,38)=19.56, p<.05$. The statistically significant differentiation of the two groups in the visual retention task confirms the second research hypothesis.

In order to assess the third hypothesis that bilingual students were expected to perform better in the inhibition control task, an independent variable analysis of variance was performed for the two groups, with a dependent variable being the three different conditions of the Stroop test. In particular, for the first condition of the Stroop test it was found that there was no statistical difference in the performance of the two groups $F(2,38)=2.09, p>.05$. In the second condition of the Stroop test, respectively, no statistically significant difference was found for the performance of the two groups $F(2,38)=6.98, p>.05$. Finally, in the third condition, $F(2,38)=19.23, p<.05$, a statistically significant difference was found, confirming the third hypothesis that bilingual students partially exhibit a significant inhibitory advantage when compared to monolingual students. The findings will be discussed in the 'Discussion' section which follows.

\section{Discussion}

The purpose of this research was to investigate the inhibitory control and executive functions of bilingual students and to compare their performance with monolingual students of the same age. Forward Digit Recall and Backward Digit Recall were used to evaluate Verbal Working Memory. The visual-spatial Working Memory was measured by the Visual Pattern Test and the Corsi Block Backward. Executive functions were examined with the Stroop Test.

The results of the research show that the two groups did not differ in their performance on working memory tasks. More specifically, the evaluation of Verbal Working Memory revealed that bilingual students did not perform better in the Forward and Backward Digit Recall sub-test. According to literature review, this finding is in line with a number of similar research studies (Adesope et al., 2010. Speidel, 1993). In particular, researchers attribute the results of the findings to the simultaneous activation of the two languages. In addition, they argue that the mechanism with which bilinguals are led to cognitive change is based, mainly, on the need to focus their attention on the language they need. Nevertheless, this finding does not reflect an advantage in their performance in verbal memory tests. Bilinguals and monolinguals did not appear to differ in performance on working memory tasks, such as the Backward Corsi block and the Backward digit recall. This research finding indicates that working memory is a separate function in itself and does not belong to all of the executive functions.

The second hypothesis of the research seemed to be confirmed as bilingual students performed better in visual memory. One possible interpretation can be attributed to the fact that bilingual students can be characterized, from birth, by a better ability to retain visual or auditory information and thus, as a result of 
this advantage, they are able to learn a foreign language more easily (Bialiss et al., 2011). On the other hand, their practice in foreign language learning may strengthen their memory and thus increase their memory span.

As concerning the screening of inhibition control, it was found that the bilingual students appeared to perform better in the third part of the assessment procedure while, at the same time, they did not differ in the first and second part of the test compared to the performance of the monolingual students. A possible interpretation may be attributed to active processing which they possess and to their continuous mental practice (Aron, 2007). Learning a foreign language from the first years of one's life is a demanding process in which the individual initially learns separate words, then grammar and syntax, and finally forms sentences. Usually, when trying to express himself or herself in a foreign language, the learner firstly thinks about what he or she wants to say, translates it and expresses it verbally or in writing, having previously suspended his or her impulse to express himself or herself in his or her native language (Aron, 2007). This continual use of inhibition, when using the foreign / second, third, etc. language(s) contributes to faster inhibition and thus to the fewer errors observed in multilinguals in the third part of the Stroop test. These findings are in line with the hypothesis put forward at the beginning of this research, as well as with the findings of other similar research (Bialystok, Luk, Peets \& Yang, 2010; Costa, Hernandez \& Sebastian-Galles, 2008). Finally, the ability to resist advanced interference is part of the inhibitory mechanism. It is well-known that the use of foreign languages gives an advantage to bilinguals, multilinguals and linguists over monolinguals - as concerning their inhibitory control (Alvarez et al., 2006; Ansaldo, Ghazi-Saidi \& Adrover-Roig, 2015).

By attempting to illustrate the complex framework of bilingualism in school populations, this study sought to clarify the relationship between working memory and executive functions in elementary school students. The above findings indicate the need to further study the relationship between working memory and executive functions in bilingual students. In that direction, it would help to provide more sensitive tools for measuring verbal working memory in bilingual populations in order to compare their performance with monolingual students. An important limitation and reflection of research is the fact that cognitive works were used to measure working memory. It has been ascertained that, in all studies examining the function of the memory, all the tasks which are applied aim at measuring short-term memory and working memory and do not fully evaluate one at the expense of the other. In addition, the implementation of similar contemporary correlational studies in bilingual adult populations could also contribute to this aim by attempting to explore - in depth - the link between working memory and executive functions. Moreover, additional measures of literacy skills, including pragmatics, phonetics, discourse analysis, and writing skills, bear a strong relation to working memory and executive functions, thus providing a clear picture of a child's cognitive profile.

Furthermore, our results, therefore, support the translanguaging goals of the class, namely the juxtaposition of two different languages within the same learning task, in a class setting. More bilingual classes can help to narrow the gap between monolingual and bilingual student's language proficiency. This is 
crucial because it will help to avoid an erroneous diagnosis and, it will also provide appropriate remediation, which will aid students who belong to the language minority to overcome their language differences. It will also help students to improve their chances of acquiring the same opportunities as the students who belong to the majority language group (de Abreu, Cruz-Santos, Tourinho, Martin \& Bialystok, 2012). Additionally, the research results raise important issues which relate to the best class practices. Supporting the continuous development of both languages is a key to providing students with a good head start to becoming bilingual and to helping them elevate the status of both languages inside and outside their educational settings.

\section{Suggestions for Future Research}

This research has important practical implications for assessing culturally and linguistically diverse children and students within the framework of a multicultural environment. Today there is a demand for a variety of methods, approaches, and techniques which are necessary so as to teach bilingual students and which are also based upon a range of principles, pedagogies, and resources for teaching and developing literacies, not only within the realm of the class but also at home with the help of their students' parents. Good, effective teaching and learning should be based on the knowledge and experiences which bilingual students bring with them to the class. In this framework, dynamic schemata of memory strategies, as mental acts, are proposed in order to enhance academic achievement and reading comprehension so as to minimize language diversity in class settings. More specifically, in the field of reading ability, the cognitive strategy of re-reading can be implemented. Reading comprehension is a complex process, which takes place at both a cognitive and at a metacognitive level. As a result, repeated reading strategies contribute to the enhancement of processing and a deeper comprehension of a text, as new skills are automated, avoiding confusion with new or similar material, and thus consolidation is achieved. Furthermore, re-reading strategies help students to understand the meaning of the text by generating new information from existing information and filling in the missing information in order to understand its meaning (Sofologi, Efstratopoulou, Kamari, Bonti \& Katsiana, 2020). As regarding the reinforcement of the understanding mechanism, it is very important to organize information into cognitive maps (lists, charts, conceptual maps). Additionally, the learner needs to be trained in developing strategies for narrative or informative text summaries (finding the main idea and key information, using -questions). The interaction with the text is also of great importance, such as for example underlining keywords, placing question marks next to unknown words (Panteliadou, 2011), etc. Another important memory strategy which can enhance school performance is the key-word method. More specifically, the "target key word" is an innovative cognitive task aimed at improving the ability to monitor text comprehension and improve academic performance (Thiede, Anderson \& Therriault, 2003). The implementation of this specific strategy allows participants to link the relevant information of the text, which they have stored in their memory, with their prior knowledge, enhancing thereby the comprehension of the specific text (Sofologi et al., 2020). 
Finally, teachers should reshape their attitudes focusing more on their training as well as their individual and professional development, thus forming a more positive in-school climate, with fewer reproaches and more praise for all students especially those with learning disabilities. It is needless to say that it is essential to develop a positive climate based on the mutual support and cooperation between the school environment and the family so that this positive interaction can work as a medium to shield, protect and promote the personality of a bilingual child. On the other hand, the professional development of teachers is of vital importance (Diamond \& Lee, 2011). Professional development encourages teachers to develop and re-organize a wider knowledge 'setting' thus becoming more knowledgeable about language and literacy development in bilingual students (Bialystok, Craik, Green \& Gollan, 2009). Furthermore, teachers need to develop and document fundamental practices building on the strengths of bilingual students in order to offer real alternatives to current policies and practices.

\section{Conclusion}

The current study is an attempt to shed light on the complex relationship between working memory and executive functions in bilingual children and to compare them (the bilingual learner) with monolingual children. According to the current research findings the use of a foreign language gives an advantage to bilinguals, when compared to monolinguals - as concerning their inhibitory control. More specifically, cognitive flexibility enables individuals to shift between different cognitive processing styles, thereby facilitates decision making, especially in environments characterized by high complexity like language (Guzman-Velez \& Tranel, 2015). Additionally, both groups did not differ in working memory measurements tasks, such as the Backward Corsi block and the Backward digit recall. This research finding indicates that working memory is a separate function and does not belong to all of the executive functions. Furthermore, the present study emphasizes on the essential practices and training that teachers must enhance in multicultural class settings in order to strengthen the academic development of bilingual children. Finally, the professional development of teachers is of vital importance in order to create an educational context which allows and empowers the fair linguistic and cultural exchange known as "bilingual and cultural awareness" (Tsokalidou, 2005; Ozfidan \& Toprak, 2019). This exchange will construct a positive school environment for the holistic development of all students, contributing to the protection of social justice, equity and human rights.

\section{Acknowledgements}

We are grateful to Kiriazi Dimitra, Special Educator, for her contribution and support in the collection of the bilingual sample. We are also grateful to the participants of the present research. 


\section{References}

Abutalebi, J., Della Rosa, P. A., Green, D. W., Hernandez, M., Scifo, P., Keim, R., \& Costa, A. (2011). Bilingualism tunes the anterior cingulate cortex for conflict monitoring. Cerebral Cortex, 22, 2076-2086. https://doi.org/10.1093/cercor/bhr287

Adesope, O. O., Lavin, T., Thompson, T., \& Ungerleider, C. (2010). A systematic review and meta-analysis of the cognitive correlates of bilingualism. Review of Educational Research, 80, 207-245. https://doi.org/10.3102/0034654310368803

Allen, L. Q. (2004). Implementing a culture portfolio project within a constructivist paradigm. Foreign Language Annals, 37, 232-239. https://doi.org/10.1111/j.19449720.2004.tb02196.x

Alvarez, J. A., Emory, E., \& Julie, A. (2006). Executive function and the frontal lobes: A meta-analytic review. Neuropsychology Review, 16, 17-42. https://doi.org/10.1007/s11065-006-9002-x

Ansaldo, A. I., Ghazi-Saidi, L., \& Adrover-Roig, D. (2015). Interference control in elderly bilinguals: Appearances can be misleading. Journal of Clinical and Experimental Neuropsychology, 37, 455-470. https://doi.org/10.1080/13803395.2014.990359

Aron, A. R. (2007). The neural basis of inhibition in cognitive control. Neuroscientist, 13, 214-228. https://doi.org/10.1177/1073858407299288

Bacha, N. N. (2019). Bilingualism as the Medium of Educational Instruction: An Exploratory Study of Student and Teachers' Views in Lebanon. International Journal of English Linguistics, 330-346. https://doi.org/10.5539/ijel.v9n3p330

Baker, C. (1993). Foundations of bilingual education and bilingualism. Academic consultant: Ofelia Garcia. Clevedon (England) \& Philadelphia: Multilingual Matters.

Berroir, P., Ghazi-Saidi, L., Dash, T., Adrover-Roig, D., Benali, H., \& Ansaldo, A. I. (2017). 'Interference control at the response level: Functional networks reveal higher efficiency in bilingual brain', Journal of Neurolinguistics, 43, 4-16. https:/ / doi.org/10.1016/j.jneuroling.2016.09.007

Bialystok, E. (2011). Reshaping the mind: Benefits from Bilingualism. Canadian Journal of Experimental Psychology, 4, 229-235. https://doi.org/10.1037/a0025406

Bialystok, E., Craik, F. I. M., Green, D. W., \& Gollan, T. H. (2009). Bilingual minds. Psychological Science in the Public Interest, 10, 89-129. https://doi.org/10.1177/1529100610387084

Bialystok, E., Luk, G., Peets, K. F., \& Yang, S. (2010). Receptive vocabulary differences in monolingual and bilingual children. Bilingualism: Language $\mathcal{E} \quad$ Cognition, 13(4), 525-531. https://doi.org/10.1017/S1366728909990423

Bligh, C., \& Drury, R. (2015). Perspectives on the "Silent Period" for Emergent Bilinguals in England. Journal of Research in Childhood Education, 29(2), 259-274. https:// doi.org/10.1080/02568543.2015.1009589

Blom, E., Küntay, A. C., Messer, M., Verhagen, J., \& Leseman, P. (2014). The benefits of being bilingual: working memory in bilingual Turkish-Dutch children. Journal of

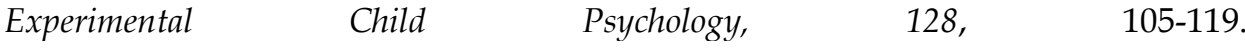
https://doi.org/10.1016/j.jecp.2014.06.007

Brophy, J. (2004). Motivating Students to Learn. New Jersey: Lawrence Erlbaum Associates.

Carlson, S. M., \& Meltzoff, A. N. (2008). Bilingual experience and executive functioning in young children. Developmental Science, 11, 282-298. https:// doi.org/10.1111/j.1467-7687.2008.00675.x 
Costa, A., Hernandez, M., \& Sebastian-Galles, N. (2008). Bilingualism aids conflict resolution: Evidence from the ANT task. Cognition, 106, 59-86. https:// doi.org/10.1016/j.cognition.2006.12.013

Coyle, D. (2018). The Place of CLIL in (Bilingual) Education. Theory Into Practice 57(3), 166-176. https:/ / doi.org/10.1080/00405841.2018.1459096

Cummins, J. (1984). Wanted: A theoretical framework for relating proficiency to academic achievement among bilingual students. In C. Rivera (Eds.) Language Proficiency and Academic Achievement. Clevedon: Multilingual Matters.

Dana-Gordon, C., Mazaux, J. M., \& Kaoua, B. N. (2014). Bilingualism and executive functions: The effect of age. Annals of Physical and Rehabilitation Medicine, 57, 152153. https://doi.org/10.1016/j.neuropsychologia.2016.08.029

de Abreu, Cruz-Santos, A., Tourinho, C. J., Martin, R., \& Bialystok, E. (2012). Bilingualism Enriches the Poor: Enhanced Cognitive Control in Low-Income Minority Children. Psychological Science 23(11), 1364-1371. https://doi.org/10.1177/0956797612443836

Della Sala, S., Gray, C., Baddeley, A., Allamano, N., \& Wilson, L. (1999). Pattern span: A tool for unwelding visuo-spatial memory. Neuropsychologia, 37, 1189-1199. https://doi.org/10.1016/S0028-3932(98)00159-6

Delliou, A., \& Zafiri, M. (2016). Developing the speaking skills of students through CLILA case of sixth grade Primary School students in Greece. Proceedings of the 5th Electronic International Interdisciplinary Conference (pp. 8-12). Prague, Czech Republic. Retrieved from www.eiic.cz.

Diamond, A., \& Lee, K. (2011). Interventions shown to aid executive function development in children 4-12 years old. Science, 333, 959-964. https://doi.org/10.1126/science.1204529

Duke, N. K. (2016). Project-Based Instruction: A Great Match for Informational Texts. American Educator, 40(3), 4-11. Retrieved from https://eric.ed.gov/?id=EJ1115458

Education Service Center Region XIII. (2009). Focus On - Explore. Education Technology $\&$ The Model of Instruction. CScope. Retrieved from http://www4.esc13.net/uploads/instructionaltech/docs/5E_Expanded_Tech_ EXPLORE.pdf.

Fried-Booth, D. L. (2002). Project work. New York: Oxford University Press.

Gathercole, S. E., \& Baddeley, A. D. (1990). Phonological memory deficits in language disordered children: Is there a causal connection? Journal of Memory and Language, 29, 336-360. https://doi.org/10.1016/0749-596X(90)90004-J

Gathercole, S. A., Tiffany, S., Briscoe, J., \& Thorn, A. (2008). Developmental consequences of poor phonological short-term memory function in childhood: a longitudinal study. Journal of Child Psychology \& Psychiatry, 46, 598-611. https://doi.org/10.1111/j.1469-7610.2004.00379.x

Georgas, G., Paraskevopoulos, H. N., Bezevegis, Z., \& Giannitsis, N. G. (1997). Greek WISC- III. Athens: Hellinika Grammata. (in Greek)

Golberg, H., Paradis, J., \& Crago, M. (2008). Lexical acquisition over time in minority first language children learning English as a second language. Applied Psycholinguistics, 29, 41-65. https://doi.org/10.1017/S014271640808003X

Gollan, T. H., \& Ferreira, V. S. (2009). Should I stay or should I switch? A cost benefit analysis of voluntary language switching in young and aging bilinguals. Journal of Experimental Psychology: Learning, Memory, \& Cognition, 35, 640. https://doi.org/10.1037/a0014981 
Greene, C. M., Braet, W., Johnson, K. A., \& Bellgrove, M. A. (2007). Imaging the genetics of executive functions. Biological Psychology, 79, 30-42. https://doi.org/10.1016/j.biopsycho.2007.11.009

Guzman-Velez, E., \& Tranel, D. (2015). Does Bilingualism contribute to cognitive reserve? Cognitive and neural perspectives. Neuropsychology, 29(1), 139-150. https://doi.org/10.1037/neu0000105

Gutek, G. L. (2003). Filozoficzne i ideologiczne podstawy edukacji, GWP, Gdańsk [English Translation: Philosophical and ideological foundations of education] (pp. 261-262).

Farrell Pagulayan, K., Busch, R. M., Medina, K. L., Bartok, J. A., \& Krikorian, R. (2006). Developmental Normative Data for the Corsi Block-Tapping Task. Journal of Clinical $\mathcal{E}$ Experimental Neuropsychology, 28(6), 1043-1052. https://doi.org/10.1080/13803390500350977

Haines, S. (1989). Projects for the EFL classroom: Resource material for teachers. Walton-onThames, UK: Nelson.

Hernandez, A. (2009). Language switching in the bilingual brain: What's next? Brain and Language, 109, 133-140. https://doi.org/10.1016/j.bandl.2008.12.005

Hoffmann, C. (2014). An Introduction to Bilingualism. London \& New York: Routledge.

Hurajova, A. (2015). An Overview of Models of Bilingual Education. Mediterranean Journal of Social Sciences, 6(6), 1-7. https:/ / doi.org/10.5901/mjss.2015.v6n6s1p186

Kane, M. J., \& Eagle, R. W. (2002). The role of prefrontal cortex in working-memory capacity, executive attention, and general fluid intelligence: an individualdifferences perspective. Psychonomic Bulletin $\mathcal{E}$ Review, 9, 637-671. Retrieved from http:/ / library.uncg.edu/

Keeton, M. T., \& Tate, J. T. (1978). Learning by Experience--what, Why, how. Michigan: Jossey-Bass.

Kilpatrick, W. H. (1925). Foundations of Method. New York: Macmillan.

Kim, K. H. S., Relkin, N. R., Lee, K. M., \& Hirsch, J. (1997). Distinct cortical areas associated with native and second languages. Nature, 388, 171-174. https:// doi.org/10.1038/40623

Kolb, D. A. (1984). Experiential Learning: Experience as the Source of Learning and Development. Englewood Cliffs, N. J.: Prentice Hall.

Kolber, M. (2017). Metoda projektu, czy tylko ornament dydaktyczny? [English Translation: The project method or just a didactic ornament?]. Retrieved from http://jows.pl/sites/default/files/Kolber_PDF.pdf.

Korosidou, E., \& Griva, E. (2013). 'My country in Europe: A Content-based Project for Teaching English as a Foreign Language to Young Learners'. Journal of Language Teaching and Research. Academy $v$ Publisher, Finland, 4(2), 229-243. https://doi.org/10.4304/jltr.4.2.229-243

Larsen-Freeman, D (2011). Techniques \& Principles in Language teaching. Oxford, Oxford University Press.

Lehtonen, M., Soveri, A., Lane, A., Järvenpää, J., de Bruin, A., \& Antfolk, J. (2018). 'Is bilingualism associated with enhanced executive functioning in adults? A metaanalytic review'. Psychological Bulletin, 144, 394-425. https:// doi.org/10.1037/bul0000142

Levine, G. S. (2004). Global simulation: A student-centered, task-based format for intermediate foreign language courses. Foreign Language Annals, 37(1), 26-36. https://doi.org/10.1111/j.1944-9720.2004.tb02170.x 
Luk, G., \& Bialystok, E. (2013). 'Biliguism is not a categorical variable: Interaction between, language proficiency and usage'. Journal of Cognitive Psychology, 25, 605-621. https://doi.org/10.1080/20445911.2013.795574

McCarty, S. (2010). Bilingual child-raising possibilities in Japan. Child Research Net: Research Papers.

Mellow, J. D. (2002). Towards Principled Eclecticism in Language Teaching: The two Dimensional Model and the Centering Principle. Teaching English as a Second or Foreign Language, 5(4), 1-17. https:// doi.org/10.5539/elt.v10n2p33

Mehisto, P. (2012). Excellence in Bilingual Education: A Guide for School Principals. Cambridge. CUP/Cambridge International Examinations.

Mehisto, P., Marsh, D., \& Frigols, M. J. (2008). Uncovering CLIL. Content and Language Integrated learning in Bilingual and Multilingual Education. Oxford: Macmillan.

Michael, E. B., \& Gollan, T. H. (2005). Being and Becoming Bilingual: Individual Differences and Consequences for Language Production. In J. F. Kroll \& A. M. B. de Groot (Eds.) Handbook of bilingualism: Psycholinguistic approaches (pp. 389-407). Oxford University Press.

Morales, J., Calvo, A., \& Bialystok, E. (2013). Working memory development in monolingual and bilingual children. Journal of Experimental Child Psychology, 114, 187-202. https://doi.org/10.1016/j.jecp.2012.09.002

Moreno-López, I., Ramos-Sellman, A., Miranda-Aldaco, C., \& Gomis- Quinto, M. T. (2017). Transforming ways of enhancing foreign language acquisition in the Spanish classroom: Experiential learning approaches. Foreign Language Annals, 50(2), 398 -409. https://doi.org/10.1111/flan.12267

Namazi, M., \& Thordardottir, E. (2010). A working memory, not bilingual advantage, in controlled attention. International Journal of Bilingual Education and Bilingualism, 13, 597-616. https://doi.org/10.1080/13670050.2010.488288

Olson, D. J. (2016). The gradient effect of context on language switching and lexical access in bilingual production. Applied Psycholinguistics, 37(3), 725756.bhttps://doi.org/10.1017/S0142716415000223

Ozfidan, B., \& Toprak, M. (2019). Cultural Awareness on a Bilingual Education: A Mixed Method Study. Multicultural Learning and Teaching, 2, 1-10. https://doi.org/10.1515/mlt-2017-0019

Panteliadou, S. (2011). Learning Disabilities and Educational Practice: What and Why. Athens: Field Publications.

Palaiologou, N., \& Dietz, G. (Eds.) (2012). Mapping the broad field of Multicultural and Intercultural Education worldwide: Towards the development of a new citizen. Cambridge: Cambridge Scholars Publishing.

Pickering, S., \& Gathercole, S. E. (2001) Working Memory Battery Test for Children (WMTBC). UK: The Psychological Corporation.

Pineda, J. E. (2010). Identifying language learning strategies: an exploratory study. GIST Education and Learning Research Journal, 4, 94-106. Retrieved from https://files.eric.ed.gov/fulltext/EJ1062624.pdf

Pliogou, V. \& Karakatsani, D. (eds.) (2020). Current trends of Pedagogical theory and practice. Democracy, citizenship and diversity. Athens: Gutenberg. (in Greek)

Robbins, T. W., \& Arnsten, A. F. (2009). The neuropsychopharmacology of frontoexecutive function: monoaminergic modulation. Annual Revision Neuroscience, 32, 267-287. https://doi.org/10.1146/annurev.neuro.051508.135535

Schneider, W., Kron-Sperl, V., \& Hünnerkopf, M. (2009). The development of young children's memory strategies: Evidence from the Würzburg Longitudinal Memory Study. European Journal of Developmental Psychology, 6, 70-99. https://doi.org/10.1080/17405620701336802 
Skehan, P. (1998). Task based Instruction. Annual Review of Applied Linguistics,18, 268286. https://doi.org/10.1017/S0267190500003585

Slavkov, N. (2014). Language attrition and reactivation in the context of bilingual first language acquisition. International Journal of Bilingual Education and Bilingualism, 18, 6-13. https://doi.org/10.1080/13670050.2014.941785

Sofologi, M., Efstratopoulou, M., Kamari, A., Bonti, E., \& Katsiana, A. (2020). Different strategies for assessing reading comprehension in adults. From alpha to omega. European Journal of Special Education Research, 7(4), 38-53. https://doi.org/10.5281/zenodo.3762660

Speidel, G. E. (1993). Phonological short memory and individual differences in learning to speak: a bilingual case study. First Language, 13, 69-91. https://doi.org/10.1177/014272379301303705

St Clair-Thompson, H. L., \& Gathercole, S. E. (2006). Executive functions and achievements in school: Shifting, updating, inhibition, and working memory. The Quarterly Journal of Experimental Psychology, 59, 745-759. https://doi.org/10.1080/17470210500162854

St Clair-Thompson, H., Stevens, R., Hunt, A., \& Bolder, E. (2010). Improving children's working memory and classroom performance. Educational Psychology, 30, 203219. https://doi.org/10.1080/01443410903509259

Stoller, F. L. (2006). Establishing a theoretical foundation for project-based learning in second and foreign language contexts. In G. H. Beckett \& M. T. Miller (Eds.) Project-based second and foreign language education: Past, present, and future (pp. 1940). Greenwich, CT: Information Age Publishing.

Skutnabb-Kangas, T. (1981). Bilingualism or Not: The Education of Minorities. Clevedon: Multilingual Matters.

Thiede, K. W., Anderson, M. C. M., \& Therriault, D. (2003). Accuracy of metacognitive monitoring affects learning of texts. Journal of Educational Psychology, 95, 66-73. https://doi.org/10.1037/0022-0663.95.1.66

Tsokalidou, R. (2005). Raising "Bilingual Awareness" in Greek Primary Schools. International Journal of Bilingual Education and Bilingualism, 8(1), 1-14. https://doi.org/10.1080/jBEB.v8.i1.pg48

Wali, A., Sproat, R., Padakannaya, P., \& Bhuvaneshwari, B. (2009). Model for phonemic awareness in readers of Indian script. Written Language \& Literacy, 12(2), 161-169. https://doi.org/10.1075/wll.12.2.02wal

Wei, L. (2005). Dimensions of bilingualism. In Li Wei (Eds.) 'The Bilingualism Reader' (pp. 2-21). London and New York: Routledge.

Yang, E. (2017) 'Bilinguals' Working Memory (WM) Advantage and Their Dual $\begin{array}{lllll}\text { Language } \quad \text { Practices'. Brain } & \text { 8ciences, }\end{array}$ https://doi.org/10.3390/brainsci7070086 